\title{
LA DIFÍCIL APLICACIÓN DE TRENTO: LAS FALTAS DE LOS CAPITULARES DE MURCIA (1592-1622)*
}

\author{
POR \\ ANTONIO IRIGOYEN LÓPEZ \\ Investigador «Ramón y Cajal», Dpto. Historia Moderna, Contemporánea y de América. \\ Facultad de Letras, Universidad de Murcia
}

\section{RESUMEN}

A través del examen de una visita episcopal al cabildo de la catedral de Murcia en 1592 y de las causas seguidas contra sus prebendados en los tribunales diocesanos en los años finales del siglo XVI y los primeros del siglo XVII, este trabajo pretende comprobar cómo fueron recibidas entre el alto clero las disposiciones del Concilio de Trento sobre la reforma del estado eclesiástico.

PALABRAS CLAVE: Concilio de Trento, reforma eclesiástica, cabildo catedralicio, Murcia, visita, faltas.

\section{THE HARD APPLICATION OF TRENT: FAULTS OF CAPITULARIES OF MURCIA (1592-1622)}

\section{ABSTRACT}

Through the examination of an episcopal visit to the Murcia cathedral chapter in 1592 and the cases against prebendaries in the diocesan court in the final years of the sixteenth century and early seventeenth century, this work aims to verify how the decrees of the Council of Trent to reform the eclesiastical state were received in the higher clergy.

\footnotetext{
* Este trabajo forma parte del Proyecto de Investigación 08653/PHCS/08: Nobilitas. Centro documental y de estudios de la nobleza del Reino de Murcia, siglos XV-XIX, financiado por la Fundación Séneca: Agencia regional de ciencia y tecnología de la Región de Murcia, cuyo IP es Juan Hernández Franco.
} 
KEY WORDS: Council of Trent, ecclesiastical reform, cathedral chapter, Murcia,
visit, faults. Recibido/Received 20-04-2009 Aceptado/Accepted 03-12-2009

Fray Miguel Salón, en su Vida de Santo Tomás de Villanueva (1487-1535), narra que éste, siendo arzobispo de Valencia, se veía incapaz de corregir los desmanes y malos hábitos de un canónigo. Cuando lo consiguió, el canónigo hizo la confesión de sus pecados, «y no duró cuatro ni seis días, sino un mes entero». ${ }^{1}$ Exageración sin duda pero, al mismo tiempo, reflejo de una realidad que, en absoluto, era desconocida para finales del siglo XV y buena parte de siglo XVI: la baja moralidad de una parte del clero secular y, entre éstos, de bastantes miembros de cabildos catedralicios. Así puede comprobarse en investigaciones sobre la escandalosa conducta de varios miembros del cabildo de Coria y en los muchos conflictos que surgían en la catedral de Palencia. ${ }^{2}$ Por lo cual, no es extraño que los prebendados, con frecuencia, fueran protagonistas de la literatura anticlerical. ${ }^{3}$

Estos textos literarios, y también los sínodos de la segunda mitad del siglo XV, mostraban una Iglesia española dominada por la secularización, absentismo, ignorancia y escasa moralidad y poca disciplina. Por esta razón, en el movimiento general de reforma que afectó a toda la iglesia desde fines del siglo XV, la elevación moral y la formación intelectual del clero fue un punto básico. ${ }^{4}$

Lo fue, evidentemente, en el Concilio de Trento que, desde sus inicios, se fijó como una de sus metas recuperar la dignidad de los eclesiásticos. ${ }^{5}$ Su objetivo prioritario fue la reformación de costumbres. Se quería acabar con el ambiente de permisividad y elevar el tono moral como lo habían hecho los reformadores protestantes, dejando sin argumentos sus críticas a la Iglesia de Roma. No se trataba tanto de refutar los ataques protestantes contra los abusos del clero católico, su excesivo apego al mundo, su falta de preparación o su poco interés pastoral, sino de acabar con ellos.

¿Cómo aplicó el alto clero los decretos de reforma emanados del Concilio de Trento y cuáles fueron sus resultados? Responder a esto es el objetivo de este estudio. Se examinarán los comportamientos de los prebendados de la ca-

${ }^{1}$ Alonso de Villegas, Fructus Sanctorum y Quinta Parte del Flos Sanctorum, Zaragoza, 1592, fols. $129 \mathrm{r}-129 \mathrm{v}$.

2 Ángel Rodríguez SÁnchez, Hacerse nadie, Cáceres, 1984; Antonio CABEZA RodríGueZ, Clérigos y señores. Política y religión en Palencia en la Edad Moderna, Palencia, 1998.

3 Julio CARo BAROJA, Las formas complejas de la vida religiosa (siglos XVI y XVII), Madrid, 1985, pp. 189-193.

${ }^{4}$ Helen Rawlings, Church, Religion and Society in Early Modern Spain, Nueva York, 2002, p. 50.

${ }_{5}^{5}$ Adriano Prosperi, El Concilio de Trento. Una introducción histórica, Valladolid, 2008, pp. 69-79. 
tedral de Murcia en los últimos años del siglo XVI y primeros del XVII. Se señalarán las faltas más comunes y se comprobará qué hizo el cabildo catedralicio ante las disposiciones tridentinas y su implicación en la reforma entre 1592 y 1622. La elección de estos límites cronológicos no es gratuita. En el primer año, Sancho Dávila, prototipo de prelado contrarreformista, ${ }^{6}$ realizó una visita a la catedral y al cabildo. ${ }^{7}$ El límite final, 1622, viene impuesto por la documentación. Ordenó el Concilio de Trento que, cuando el obispo quería proceder contra un capitular, debía ir acompañado de adjuntos elegidos por el cabildo. ${ }^{8}$ De esa manera, cada vez que el provisor quería iniciar un proceso, debía solicitar que el cabildo nombrara un adjunto para participar en la causa y esto quedaba reflejado en las actas capitulares, de forma más o menos regular, con noticias sobre el implicado y sobre la falta cometida. Pero en 1622, el obispo Antonio Trejo logró llegar a un acuerdo con el cabildo: se nombraría un capitular para que asistiese a las causas durante seis meses. De tal modo que el cabildo de la catedral de Murcia haría este nombramiento en los primeros días de enero y julio. $\mathrm{Al}$ desaparecer la necesidad de nombrar adjuntos en las causas incoadas en el tribunal diocesano contra prebendados, no aparecerán en las actas capitulares, salvo algún caso aislado, referencias a las faltas.

\section{AIRES DE REFORMA}

El Concilio de Trento, además de su programa de reformas, pretendió separar al clero de forma nítida del resto de la sociedad. La creciente de centralización de la Iglesia favoreció en varios lugares el programa de reformas. ${ }^{9}$ Eso contribuyó a reforzar el papel hegemónico y director de la Iglesia sobre el conjunto de la sociedad. ${ }^{10}$

Había que predicar con el ejemplo, y en el Antiguo Régimen una imagen valía más que mil palabras. La Iglesia debía corregir las desviaciones muy extendidas en la primera mitad del siglo XVI, desde La Mancha hasta Cataluña. ${ }^{11}$

\footnotetext{
${ }^{6}$ Francisco Candel Crespo, Un obispo postridentino: don Sancho Dávila y Toledo (1546-1625), Ávila, 1968.

${ }^{7}$ Francisco José García Pérez (ed.), La visita a la catedral de Murcia del obispo Sancho Dávila, año 1592, Murcia, Universidad de Murcia, 2000.

${ }^{8}$ Ignasi FERnÁndez TERriCABras, Felipe II y el clero secular. La aplicación del Concilio de Trento, Madrid, 2000, p. 311.

${ }^{9}$ Heinrich LuTZ, Reforma y Contrarreforma, Barcelona, 1998, pp. 120-121.

10 John Bossy, «The Counter-Reformation and the people of Catholic Europe», Past and Present, 97 (1970), pp. 51-70.

11 Sara T. NALle, God in La Mancha. Religious Reform and the people of Cuenca, 1500-1650, Baltimore, 1992, pp. 70-104; Joan BADA, Situació religiosa de Barcelona en el segle XVI, Barcelona, 1970; Henry KAmEn, Cambio cultural en la sociedad del Siglo de Oro. Cataluña y Castilla, siglos XVIXVII, Madrid, 1998, pp. 304-309.
} 
San Juan de Ávila estimó acción prioritaria la reforma intelectual y moral del clero secular como condición indispensable para el éxito de la renovación religiosa de la sociedad. ${ }^{12}$ Como una de las causas de la decadencia moral del clero era su escasa formación, el Concilio de Trento pidió la apertura de seminarios diocesanos para una mejor formación intelectual y pastoral de los clérigos, de modo que comprendieran la importancia de su ministerio y la necesidad de llevar una vida santa y honesta. Estos proyectos fracasaron en numerosos lugares pues pocas veces se lograron reunir los fondos necesarios para la fundación de los seminarios..$^{13}$

Para emprender una reforma radical de los eclesiásticos se puso en marcha una mayor centralización, que reforzó la estructura jerárquica de la Iglesia. ${ }^{14}$ Los encargados de realizarla debían ser obispos al estilo de Carlos Borromeo o Gian Matteo Giberti. ${ }^{15}$ Era necesario, por tanto, fortalecer su poder sobre el clero diocesano. En este contexto se inscribe toda la acción episcopal: la celebración de sínodos, la creación de seminarios diocesanos, las visitas pastorales y la revitalización de los tribunales diocesanos. ${ }^{16}$ Aun con estos medios, la aplicación de la reforma encontró grandes dificultades en la Europa católica. ${ }^{17}$

Sabemos que una de las principales oposiciones al poder episcopal provino de los cabildos catedralicios, como ha expuesto Ignasi Fernández Terricabras en su modélica obra sobre el Concilio de Trento. En ella, retomando trabajos clásicos sobre la resistencia de los cabildos a las reformas tridentinas, ha incorporado las nuevas herramientas conceptuales de la teoría de la confesionalización, su recepción en España y el papel desempeñado por la Monarquía católica en este proceso. ${ }^{18}$

Desde las primeras sesiones del Concilio, los cabildos catedralicios hispanos fueron conscientes del peligro que les podía suponer un fortalecimiento del poder episcopal. ${ }^{19}$ Hay que recordar que, desde la Edad Media, se habían converti-

12 Juan DE ÁvILA, Escritos sacerdotales, Madrid, 2000; Juan EsQUeRDA BIFET, Introducción a la doctrina de San Juan de Ávila, Madrid, 2000; Florencio SÁNCHEZ Bella, La reforma del clero secular en San Juan de Ávila, Madrid, 1970.

13 Francisco Martín HernándeZ, «Fundación de los primeros seminarios españoles», Hispania Sacra, 16 (1963), pp. 1-20.

${ }^{14}$ RaWlings, Church, Religion and Society, pp. 54-55.

${ }_{15}$ Michael A. Mullet, The Catholic Reformation, Nueva York, 1999, pp. 132-141.

${ }^{16}$ R. Po-CHIA Hsia, The world of Catholic renewal, 1540-1770, Cambridge, 1998, p. 116.

${ }_{17}$ Luise SCHORN-SchÜTte, «The 'New Clergies' in Europe: Protestant Pastors and Catholic Reform Clergy after the Reformation», en Bridget Heal y Ole Peter Grell (eds.), The Impact of the European Reformation: Princes, Clergy and People, Londres, 2008, pp. 114-116.

${ }^{18}$ FERnÁNDEZ TERRICABRAs, Felipe II y el clero secular, pp. 291-359.

${ }^{19}$ Feliciano CERECEDA, «El litigio de los cabildos españoles y su repercusión en las relaciones con Roma (1551-1556)», Razón y fe, 130 (1944), pp. 215-234; Tomás MARín MARTínEZ, «Primeras repercusiones tridentinas: el litigio de los cabildos españoles. Su proceso en la diócesis de Calahorra», His- 
do en auténticos contra-poderes del obispo. ${ }^{20}$ Esta situación se había generado, entre otros motivos, por el elevado absentismo episcopal, de tal modo que los cabildos se habituaron a ser, más o menos, autónomos. Eso sucedió en el de la catedral de Murcia en la primera mitad del siglo XVI. El prelado Mateo Lang durante todo su episcopado (1513-1540) no llegó a pisar la diócesis de Cartagena. ${ }^{21}$

Los cabildos habían llegado a ser una pieza fundamental en el entramado del poder local, pues gozaban de prestigio, riqueza y preeminencia social y la mayor parte de sus componentes pertenecían a los grupos oligárquicos. Alfonso de Valdés llegó a calificarlos como hospicios de nobleza. ${ }^{22}$ Cada cabildo era una especie de pequeño estado, con su presupuesto, sus servicios, su jerarquía. ${ }^{23}$ No puede extrañar su firmeza ante cualquier injerencia externa y su oposición a que recortaran sus privilegios y prerrogativas. Trento suponía para ellos el final de una forma de vida a la que no estaban dispuestos a renunciar y por esta razón se opusieron con fuerza a las reformas tridentinas. ${ }^{24}$

Por esta razón, desde los primeros momentos los cabildos catedralicios se niegan a que pudieran realizarse las visitas de los obispos decretadas en 1547 y 1552 con el argumento de que el concilio no podía tener validez si el Papa no lo confirmaba de forma explícita. Surgen, por esta razón, numerosos conflictos en Castilla entre los prelados y los capitulares y entre los que apoyaban a unos y otros, es decir, entre el rey y el papa. En la última etapa del concilio, verá la luz un decreto de reforma ambivalente puesto que, si bien se establece la visita episcopal, por otro lado se limita la actuación de los prelados porque siempre deben proceder acompañados de dos adjuntos capitulares. Concluye Fernández Terricabras que, si bien es verdad que Trento supone un hito decisivo en el control de los cabildos por los obispos, aquéllos dispondrán de varios mecanismos de resistencia que utilizarán con profusión desde la misma clausura del concilio. ${ }^{25}$ De esta manera, a lo largo de toda la Edad Moderna los conflictos entre prelados y cabildos serán una constante en los diferentes ámbitos de la Monar-

pania Sacra, 1 (1948), pp. 325-349; Demetrio MANsiLla, «Reacción del cabildo de Burgos ante las visitas y otros actos de jurisdicción intentados por sus obispos (siglos XIV-XVII)», Hispania Sacra, 10 (1957), pp. 135-159; José GoÑí GAZTAMBIDE, «Los cabildos españoles y la confirmación del Concilio de Trento», Annuarium Historiae Conciliorum, 7 (1975), pp. 425-458.

${ }^{20}$ Fernández TERriCABras, Felipe II y el clero secular, p. 301.

21 Pedro Díaz Cassou, Serie de los obispos de Cartagena, Murcia, 1977 (facsímil de la edición de 1895), pp. 76-80.

22 Tarsicio de AzConA, «Reforma del episcopado y del clero», Historia de la Iglesia en España, vol III-1 ${ }^{\circ}$ : La Iglesia en la España de los siglos XV y XVI, dir. Ricardo García Villoslada, Madrid, 1979, p. 169.

23 George Desdevises du DeZÉrt, La España del Antiguo Régimen, Madrid, 1989, p. 53.

24 RAWLINGS, Church, Religion and Society, pp. 56-58; FERNÁNDEZ TERRICABRAS, Felipe II y el clero secular, pp. 300-349.

25 FERnÁndez TERriCABras, Felipe II y el clero secular, pp. 291-312. 
quía Hispana, tal y como han puesto de manifiesto numerosos trabajos, ${ }^{26}$ de los que podría ser paradigma la pugna entre el arzobispo Aliaga y el cabildo catedralicio de Valencia. 27

Las visitas episcopales a los cabildos catedralicios formaban parte del programa de reforma del clero, necesario la renovación católica. Los obispos hispanos se lanzarán a imponer la disciplina eclesiástica, según el espíritu y la legislación del Concilio de Trento, sin detenerse en otras cuestiones doctrinales. ${ }^{28}$ Se buscaba el obispo ideal, el párroco ideal, el clérigo ideal. ${ }^{29}$

La prioridad era profesionalizar al clero..$^{30}$ El Concilio de Trento, magnificando el ministerio sacerdotal, buscaba alejar del mundo al clero. Debía influir

\footnotetext{
${ }^{26}$ Una visión panorámica de todo este asunto se puede encontrar en: Rafael MARín LóPEZ, «Historiografía sobre cabildos eclesiásticos. Estado de la cuestión y perspectivas de investigación», en A. L. Cortés PeÑa y M. L. López-Guadalupe MuÑoz (eds.), La Iglesia española en la Edad Moderna. Balance historiográfico y perspectivas, Madrid, 2007, pp. 79-112. De igual manera son útiles: Miguel Ángel de BunEs IBARRA, «La Iglesia en la España de los Austrias: una aproximación a las tendencias historiográficas», en J. ANDRÉs-GALLEGO (ed.), La Historia de la Iglesia en España y el mundo hispánico, Murcia, 2001, pp. 191-208; Arturo Morgado García, «El clero en la España de los siglos XVI y XVII. Estado de la cuestión y últimas tendencias», Manuscrits, 25 (2007), pp. 75-100, Antonio DomínGUEZ ORTIZ, Las clases privilegiadas del Antiguo Régimen, Madrid, 1989, pp. 245-249.

${ }^{27}$ Emilio Callado Estela, Iglesia, poder y sociedad en el siglo XVII. El arzobispo de Valencia fray Isidoro Aliaga, Valencia, 2001, pp. 207-246.

28 José SÁnchez Herrero, Historia de la Iglesia en España e Hispanoamérica, Madrid, 2008, pp. 201-202.

29 José Ignacio Tellechea IdíGoras, El obispo ideal en el siglo de la Reforma, Roma, 1963; Hubert JEDIN, «¿Ha creado el Concilio de Trento la imagen-modelo de sacerdote?», en John CopPENS (dir.), Sacerdocio y celibato, Madrid, 1982; Pierre HuRTUBISE, «Le prête tridentin: idéal et réalité», en Homo Religiosus: autour de Jean Delumeau, París, 1997; Ignasi Fernández TerRICABras, «Entre ideal y realidad: las élites eclesiásticas y la reforma católica en la España del siglo XVI», en Nuno Monteiro, Pedro Cardim y Mafalda S. DA Cunha (coords.): Optima Pars: Elites Ibero-Americanas do Antigo Regime, Lisboa, 2005; Patrick J. O'BANION, «A priest who appears god: manuals of confession and the construction of clerical identity in Early Modern Spain», en Wim JANSE y Barbara PITKIN (eds.), The formation of clerical and confessional identities in Early Modern Europe, Leiden, 2006, pp. 333-348; José Luis BETRÁN MoYA «El pastor de almas: la imagen del buen cura a través de la literatura de instrucción sacerdotal en la Contrarreforma española», en Eliseo SERRANo, Antonio Luis CORTÉs y José Luis BETRÁn (coords.), Discurso religioso y Contrarreforma, Zaragoza, 2005, pp. 161201; Antonio IRIGOYEN LÓPEZ, «Los tratados de perfección sacerdotal y la construcción de la identidad social del clero en la España del siglo XVII», Hispania, 230 (2008), pp. 707-734.

${ }^{30} \mathrm{El}$ concepto de profesionalización del clero está teniendo gran difusión en la última historiografía. Véanse, entre otros: Wietse de BoER, «Professionalization and clerical identity: notes on the early modern catholic priest», en JANSE y PITKIN (eds.), The formation of clerical, pp. 369-378; Idem, La conquista dell'anima. Fede, disciplina e ordine pubblico nella Milano della Controriforma, Turín, 2004; Angelo TURCHINI, «La nascita del sacerdozio come professione», en Paolo PrODI (dir.), Disciplina dell'anima, disciplina del corpo e disciplina della società tra medioevo ed età moderna, Bolonia, 1994, pp. 225-256; Maurizio SANGalli (ed.), Pastori, pope, preti, rabbini. La formazione del ministro di culto in Europa (secoli XVI-XIX), Roma, 2005; Arturo MorGADO GARCía, «El estamento eclesiástico en la Europa moderna», en Antonio Luis CoRTÉs PEÑA (coord.), Historia del cristianismo, III: el
}

Hispania Sacra, LXII

125, enero-junio 2010, 157-179, ISSN: 0018-215-X 
sobre él, pero sin estar en él. Los clérigos eran ministros de Dios, cuyo reino no era de este mundo. Lo fundamental era convencerlos de la alta dignidad de su misión y de que su modo de vida ejemplar era su mejor testimonio. Uno de los principales desvelos del prelado, encargado de realizar las exigencias reformadoras, era corregir las conductas y comportamientos desordenados ${ }^{31}$ Como recogían las Constituciones Sinodales del obispado de Cartagena de 1583, «el sacerdote debe ser el espejo donde se miren todos los fieles».32

\section{La visita al CABildo de la Catedral de Murcia}

El cabildo de Murcia podía considerarse como mediano. Estaba formado por 34 prebendas aunque, en realidad, eran 33 miembros puesto que una canonjía estaba reservada al Santo Oficio de la Inquisición. En razón de una rígida jerarquía y separación entre sus miembros, puede hablarse de dos grandes grupos. Los niveles superiores eran compartidos por cinco Dignidades, Deán, Arcediano de Lorca, Arcediano de Cartagena, Chantre, Tesorero y Maestrescuela, y siete canónigos. Mientras que integraban los cuerpos inferiores ocho racioneros y doce medio-racioneros. Las distintas categorías se fijaban en función de su prebenda con los derechos y las rentas que recibían. Existían igualmente diferencias sociales entre los dos grandes bloques del cabildo. Dignidades y canónigos solían pertenecer a la nobleza. Los racioneros y los medio-racioneros se reclutaban entre los grupos sociales intermedios en una sociedad con una movilidad ascendente. En el cabildo catedralicio había relaciones sociales verticales y horizontales de todo tipo: parentesco, patronazgo, clientelismo, amistad... y eso complicaba su funcionamiento. ${ }^{33}$

Los cabildos de la mitad sur peninsular eran hostiles y el de la catedral de Murcia fue especialmente conflictivo. ${ }^{34}$ En su conjunto, los capitulares formaban una elite local, con frecuencia enfrentada a los obispos. Tenían ventaja pues contaban con el factor tiempo a su favor. Los obispos pasaban, mientras que el cabildo y los capitulares permanecían. ${ }^{35}$

mundo moderno, Madrid, 2006, pp. 465-508; Mario RosA, Clero cattolico e società europea nell'età moderna, Roma-Bari, 2006; Federico Palomo, A Contra-Reforma em Portugal, 1540-1700, Lisboa, 2006; Maurizio SANGaLli, «La formación del clero católico en la Edad Moderna. De Roma, a Italia, a Europa», Manuscrits, 25 (2007), pp. 101-128.

${ }^{31}$ Rawlings, Church, Religion and Society, pp. 54-73.

32 Antonio Irigoyen López y José Jesús García Hourcade (eds.), Constituciones sinodales de la Diócesis de Cartagena de 1583, Murcia, 2005, p. 273.

${ }^{33}$ Antonio IRIGOYen LóPEZ, Entre el Cielo y la Tierra, entre la Familia y la Institución. El cabildo de la catedral de Murcia en el siglo XVII, Murcia, 2001.

${ }^{34}$ Domínguez ORTIZ, Las clases privilegiadas, p. 218.

35 Juan HeRnández Franco, Cultura y limpieza de sangre en la España moderna, Murcia, 1996, p. 43. 
El apego de los prebendados de la catedral de Murcia durante el siglo XVI a los asuntos mundanos se confirma con creces. Varios capitulares participaron en la revuelta de las Comunidades. El arcediano de Lorca, Gil Rodríguez de Junterón, fue uno de los dirigentes que quedó excluido del perdón real. ${ }^{36}$ En las décadas siguientes varios prebendados se vieron implicados en pendencias y querellas surgidas por la lucha de bandos. ${ }^{37}$ En el último gran conflicto en la ciudad de Murcia, en las segunda mitad del siglo, el enfrentamiento Sotos contra Riquelmes, participaron varios prebendados y alguno de ellos fue condenado como judaizante. 38

La limpieza de sangre y el creciente proceso de elitización que experimentó la institución capitular incrementaron los conflictos internos. Hubo un progresivo distanciamiento entre el grupo superior del cabildo, los dignidades y canónigos, y el inferior, los racioneros, enteros y medios.

Se comprueba, por tanto, que en el cabildo de Murcia durante el siglo XVI hubo inestabilidad y tensión permanentes. No era, pues, el mejor clima para una reforma. $\mathrm{Si}$, de acuerdo con las medidas aprobadas en Trento, la vida de los clérigos debía de ser ejemplo para el resto de la sociedad, debía serlo más la de los que ocupaban los puestos más altos de la diócesis, considerados mejor preparados y con una posición ansiada por muchos eclesiásticos. Los capitulares de la Santa Iglesia de Cartagena eran el objetivo de los obispos que llegaban con los nuevos vientos de la reforma. ${ }^{39}$

Eso se propuso la visita del obispo Sancho Dávila al cabildo en 1592.40 De acuerdo con los capitulares, se redactó un interrogatorio. Los prebendados tenían que responder sobre su ejercicio espiritual y sobre su vida. En cuanto a vida y costumbres, se les preguntaba si se dedicaban al juego, si tenían tratos con mujeres y si salían de noche. De las trece preguntas de que constaba el interrogatorio, tres se referían a los hábitos y costumbres de los capitulares:

Si ay alguno que este en peccado publico, u tenga en cassa perssonas sospechosas escandalosas.

Si ay alguno que sea tablaxero, taur, u tratante en cosas ylicitas.

\footnotetext{
36 John B. Owens, Rebelión, Monarquía y oligarquía murciana en la época de Carlos V, Murcia, 1980 , pp. 59-61.

${ }^{37}$ Antonio IRIGOYEn LóPEZ, «Aspectos eclesiásticos de la Murcia del emperador: el obispo y su cabildo», en Carlos V. Europeismo y Universalidad, Madrid, 2001, vol. IV, pp. 1371-1385.

38 Jaime Contreras, Sotos contra Riquelmes, Madrid, 1992, pp. 224-236.

39 Antonio Irigoyen López y José Jesús García Hourcade, Visitas ad limina de la diócesis de Cartagena, 1598-1901, Murcia, 2001

40 Antonio IrIGOYen LóPeZ y José Jesús García HourCade, «Aplicaciones tridentinas: la visita del obispo Sancho Dávila al cabildo de la catedral de Murcia (1592)», Investigaciones Históricas, 22 (2001), pp. 11-22.
}

Hispania Sacra, LXII

125, enero-junio 2010, 157-179, ISSN: 0018-215-X 
Si ay alguno que ande de noche con habito desonesto, acuchilladizo y en su trato de lenguaje sucio u perjudicial. .1

Es decir, la cuestión era descubrir si entre los miembros del cabildo había comportamientos públicos escandalosos. Porque la gravedad de los pecados y las faltas quedaban aumentadas mediante una especie de socialización del pecado. ${ }^{42}$ En la vida urbana de fines del siglo XVI, la privacidad prácticamente no existía y cualquier noticia era «pública y notoria», por emplear el lenguaje de la época. Los comportamientos poco correctos de personas principales eran detectados y conocidos. Su descubrimiento minaba el prestigio social del infractor. Pero, lo que es aun más importante, por un efecto de sinécdoque, el pecado cometido por la persona individual también ponía en tela de juicio y comprometía el prestigio de la institución a la que pertenecía. Por eso, algunos prebendados optaron por negar la realidad. Otros se ampararon en la ignorancia de quien no presta oídos a las habladurías. No dudaron otros en acusar. A alguno se le escapó lo que no debía y contestó «que no sabe cosa y que de lo pasado y enmendado se le a mandado no diga».43

Esta confidencia revela la actitud del cabildo ante la visita: desvelar lo menos posible. Si los cabildos temían las visitas era porque eran conscientes de que todos los problemas latentes podían emerger de forma abrupta. ${ }^{44}$ Los prelados chocaban con las reticencias de una institución a la que no le agradaba tener que responder de sus actuaciones colectivas e individuales. Si en las causas contra capitulares los delitos quedaban restringidos al acusado, en las visitas las faltas y las manchas no eran sólo de las personas, sino también de la institución que no las había corregido. También hay que considerar que el propio hecho de la realización de la visita suponía un fuerte varapalo a la autoridad del cabildo y de sus intengrantes. No podían permitir que nadie les amonestase sobre la manera de gobernar la catedral y que se entrometiera en su vida y costumbres.

Debe insistirse en que la razón más importante que explica esta resistencia era que el propio cabildo sabía que entre las personas que lo componían, existían importantes conflictos de todo tipo que saldrían a la superficie a poco que se indagara. La apariencia de normalidad y de control quedaría rota y sería un argumento más para que el superior limitara su autonomía.

Por consiguiente, se apelará al sentimiento de unión y a la privilegiada condición de prebendado para resistir las ansias de conocimiento de su prelado. De

\footnotetext{
${ }^{41}$ Archivo de la Catedral de Murcia (en adelante, ACM), Legajo (en adelante, Leg.) 295, $\mathrm{n}^{\circ} 87$.

42 José María Soto RÁbAnos, «Visión y tratamiento del pecado en los manuales de confesión de la Baja Edad Media hispana», Hispania Sacra, 118 (2006), pp. 444-445.

43 ACM, Leg. Adjuntos, Autos de la visita del obispo Sancho Dávila, año 1592.

44 Un buen ejemplo se puede ver en: CABEZA, Clérigos y señores, pp. 273-284.
} 
ahí la recomendación del cabildo a sus miembros para que no contaran todo. Sin embargo, estos llamamientos a la unidad fracasaban por las tensiones corporativas y los conflictos personales.

Las faltas registradas vienen condicionadas por las preguntas del cuestionario y se reducen básicamente a dos: juego y sexo. En la Tabla 1 se muestran con sus infractores.

Tabla $\mathbf{n}^{0} 1$

Faltas de los prebendados según la visita del obispo Dávila

\begin{tabular}{|l|l|c|}
\hline Nombre & \multicolumn{1}{|c|}{ Falta } & $\begin{array}{c}\text { Número de } \\
\text { acusaciones }\end{array}$ \\
\hline Medio Racionero Saorín de Loaysa & Juego, Amancebamiento & 7 \\
\hline Racionero Rodrigo García de Cáceres & Juego & 4 \\
\hline Medio Racionero Martín Ponce & Trato con mujeres & 2 \\
\hline Medio Racionero Andrés Hortelano & Juego & 2 \\
\hline Arcediano de Cartagena Esteban Guil Riquelme & Juego & 1 \\
\hline Medio Racionero Adrián Martínez & Trato con mujeres & 1 \\
\hline Medio Racionero Pedro Ortega & Trato con mujeres & 1 \\
\hline Racionero Pedro Villacis & Trato con mujeres & 1 \\
\hline Total & 8 faltas & 19 \\
\hline
\end{tabular}

Fuente: ACM, Leg. Adjuntos, Autos de la visita del obispo Sancho Dávila, año 1592.

El grado de la falta es difícil de determinar porque no se sabe si se trataba de unos comportamientos generalizados o esporádicos; ni siquiera se sabe si se habían corregido ya. La única forma de intentar calibrar las acusaciones ha de venir del número de testimonios como recoge la tabla 2. Estas informaciones, además, ofrecen una panorámica muy esclarecedora.

Hay diecinueve acusaciones. El racionero Saorín es acusado de dos delitos (juego y amancebamiento) por seis de sus compañeros, de los cuales sólo uno le acusa a la vez de ambos delitos: en total, cinco acusaciones de juego y dos, de amancebamiento, lo que representa el 37 por 100 de todas las denuncias. Tres miembros del cabildo acusan al racionero García Cáceres de organizar juego, y el propio acusado así lo reconoce en su testimonio. Hay dos testimonios contra el racionero Ponce de tener tratos con mujeres y otros dos contra el medio-racionero Ortelano de ser un tahúr. El resto de los acusados, cuatro miembros del cabildo, es acusado una vez (uno por juego y los otros tres de tener tratos con mujeres). La coherencia y concordancia de los testimonios lleva a 
otorgar cierto grado de veracidad a las acusaciones levantadas contra los tres primeros. De los restantes, es difícil saber si se trataba de difamaciones o de hechos ciertos.

Tabla $\mathbf{n}^{\circ} 2$

Interrogatorio sobre las costumbres de los prebendados, 1592

\begin{tabular}{|c|c|}
\hline DEPONENTE & TESTIMONIO \\
\hline Deán Alberto Lisón & Que no sabe nada de esto. \\
\hline Esteban Guil Riquelme, AC & Que no sabe nada de esto \\
\hline Antonio de Roda, $\mathrm{AL}$ & Que no sabe nada de esto. \\
\hline $\mathrm{C}^{\circ}$ Alonso Rodríguez Navarro & $\begin{array}{l}\text { Que los sres. Garcia y Saorin de Loaysa tienen tablage en } \\
\text { sus casas con escandalo y notas. }\end{array}$ \\
\hline \multirow[t]{2}{*}{$\mathrm{C}^{\mathrm{o}}$ Pedro Martínez de Alarcón } & $\begin{array}{l}\text { Que los sres. Saorin, Martin Ponce y el maestro de capilla } \\
\text { tienen opinion de amancebados y escandalizan don esta } \\
\text { sospecha. }\end{array}$ \\
\hline & $\begin{array}{l}\text { Que el racionero Garcia tiene tablageria y Saurin y que el } \\
\text { arcediano de Cartagena guega segun dice Galera mayor- } \\
\text { domo del cabildo. }\end{array}$ \\
\hline $\mathrm{C}^{\mathrm{o}}$ Antonio Coello & $\begin{array}{l}\text { Que a poco que esta aqui que no lo sabe, que a oido quel } \\
\text { rationero Saurin juega. }\end{array}$ \\
\hline \multirow[t]{2}{*}{$\mathrm{C}^{\mathrm{o}}$ Alonso Tirado } & $\begin{array}{l}\text { Que a oido de Saurin y que aora le parece esta corregido } \\
\text { que convendria echar del lugar una muger sospechosa que } \\
\text { a tenido en su casa. }\end{array}$ \\
\hline & $\begin{array}{l}\text { Que no sabe mas de que el racionero Hortelano tiene opi- } \\
\text { nion de taur y es necesario amonestarle que no lo sea. }\end{array}$ \\
\hline $\mathrm{R}^{\circ}$ Rodrigo García de Cáceres & $\begin{array}{l}\text { Que este verano se juntaron en su casa a jugar y por averle } \\
\text { mandado esto señores capitulares que no pasase adelante } \\
\text { se quedo y no sabe mas de esto. }\end{array}$ \\
\hline \multirow[t]{2}{*}{$\mathrm{R}^{\circ}$ Pedro Villacis } & $\begin{array}{l}\text { Que no lo sabe y que no da credito a lo mucho que en el lu- } \\
\text { gar se charla. }\end{array}$ \\
\hline & $\begin{array}{l}\text { Que no sabe cosa y que de lo pasado y enmendado se le a } \\
\text { mandado no diga. }\end{array}$ \\
\hline $\mathrm{R}^{\circ}$ Hernando Hurtado Nieto & $\begin{array}{l}\text { Que solo a oido lo que toca al racionero Saurin aunque } \\
\text { tambien a oido que se a remediado por aver estado malo y } \\
\text { averse confesado a instancias del cabildo. }\end{array}$ \\
\hline $\mathrm{mR}^{\circ}$ Diego Blasco & Que no sabe nada de esto. \\
\hline Medio Racionero Martín Ponce & $\begin{array}{l}\text { Que no sale de noche el dicho testigo y asi no encuentra a } \\
\text { naide ni sabe de esto. }\end{array}$ \\
\hline $\mathrm{mR}^{\circ}$ Juan Ponce & Que no conoce a quien a de noche ni sabe nada de esto. \\
\hline
\end{tabular}




\begin{tabular}{|c|c|}
\hline DEPONENTE & TESTIMONIO \\
\hline $\mathrm{mR}^{\circ}$ Francisco de Guevara & Que ni a visto ni a oido cosa que toque a esta pregunta. \\
\hline $\mathrm{mR}^{\circ}$ Salvador de Aranda & Que no sabe de naide que tenga tal vicio. \\
\hline $\mathrm{mR}^{\circ}$ Pedro Ortega & Que no lo sabe. \\
\hline \multirow[t]{3}{*}{$\mathrm{mR}^{\circ}$ Adrián Martínez } & Que no sabe cosa sino mucha virtud de todos. \\
\hline & $\begin{array}{l}\text { Que de presente no sabe que ay entre los señores capitula- } \\
\text { res tablagero ni tahur ninguno }\end{array}$ \\
\hline & $\begin{array}{l}\text { Que no sabe ni a visto a nadie que salga porque el dicho } \\
\text { testigo no sale de noche ni tiene este trato. }\end{array}$ \\
\hline \multirow[t]{3}{*}{$\mathrm{mR}^{\circ}$ Jerónimo Amad } & $\begin{array}{l}\text { Que no puede saberlo porque no anda aberiguando vidas } \\
\text { agenas. }\end{array}$ \\
\hline & Que las pascuas suelen jugar alguna mijeria (sic). \\
\hline & $\begin{array}{l}\text { Que aunque a mas de cinquenta y quatro años que viene a } \\
\text { maitines no topava si sabe de quienes de los señores capi- } \\
\text { tulares saliesen de noche de los que aora son vivos que en } \\
\text { tiempos pasados algunos andavan. }\end{array}$ \\
\hline \multirow[t]{2}{*}{$\mathrm{mR}^{\circ}$ Diego Maineta } & $\begin{array}{l}\text { Que tampoco sabe cosa publica que es el dicho testigo con- } \\
\text { fesor y no habla nunca de estas cosas. }\end{array}$ \\
\hline & Que no sabe dello porque salido de la yglesia se va al campo. \\
\hline $\mathrm{mR}^{\circ}$ Bartolomé Fernández & Que no sabe quien juebe con escandalo. \\
\hline $\mathrm{mR}^{\circ}$ Luis Ballesteros & $\begin{array}{l}\text { Que tampoco sabe sino que todos viven bien y exemplar- } \\
\text { mente. }\end{array}$ \\
\hline \multirow[t]{2}{*}{$\mathrm{mR}^{\circ}$ Bartolomé Villalobos } & $\begin{array}{l}\text { Que los sres. Ortega, Martin Ponce, Adrian Martinez y Vi- } \\
\text { llacis a oydo decir que ay publicidad con algun escandalo } \\
\text { con algunas mugeres de que parece mal y tienen necesidad } \\
\text { de reparo y ansimesmo ay que enmendar en los arcedianos } \\
\text { (sic) que entran en cierta casa sospechosa de que ay mur- } \\
\text { muracion. }\end{array}$ \\
\hline & $\begin{array}{l}\text { Que al presente no las ay y que la a avido en las casas de } \\
\text { los racioneros Garcia y Saorin y que el racionero Ortelano } \\
\text { trata del juego y tiene necesidad de reparo porque algunas } \\
\text { vezes falta a visperas. }\end{array}$ \\
\hline \multirow[t]{3}{*}{$\mathrm{mR}^{\circ}$ Andres Ortelano } & Que no sabe cosa que sea de escandalo. \\
\hline & No sabe que sea naide tablagero ni taur. \\
\hline & $\begin{array}{l}\text { Que ay gran compostura entre todos estos señores capitu- } \\
\text { lares y que por el gran calor sale alguna noche de verano y } \\
\text { esto es con habito decente que podria andar de dia. }\end{array}$ \\
\hline
\end{tabular}

Leyenda: AL: Arcediano de Lorca; AC: Arcediano de Cartagena; $\mathrm{C}^{\circ}$ : Canónigo; $\mathrm{R}^{\mathrm{o}}$ : Racionero; $\mathrm{mR}^{\circ}$ : Medio racionero. Fuente: ACM, Leg. Adjuntos, Autos de la visita del obispo Sancho Dávila, año 1592. 
En todo caso, hay que significar que en lo que al juego se refiere, la frontera entre lo tolerable y lo prohibido era muy tenue. El límite estribaba en las compañías, las actitudes y la existencia de apuestas. Pero el predominio del juego como una de las faltas principales de los capitulares reflejaba un comportamiento general al conjunto de la sociedad murciana. En los datos que ofrece Ruiz Ibáñez sobre tipología y frecuencia de los delitos en la ciudad de Murcia para el año 1590 podemos comprobar que el juego representa el $48 \% .{ }^{45} \mathrm{El}$ juego aparecía entre las principales faltas del clero cordobés en el siglo XVII, y en el clero sevillano durante el siglo XVIII. ${ }^{46}$

Estas conductas poco ortodoxas se detectaban, por lo tanto, en ocho miembros del cabildo. Si se toma como referencia que el cabildo contaba con 33 beneficiados titulares, el $24 \%$ tenía algún tipo de falta. Sin embargo, este porcentaje hay que reducirlo porque varios prebendados tenían coadjutores, de ahí que los que cometieron faltas representarían una sexta parte del cabildo.

Llama poderosamente la atención que la mayoría de los acusados, siete, pertenecieran a los estratos inferiores. Eran racioneros enteros y medios. Sólo hay un acusado entre las dignidades y ningún canónigo.

De la tabla 2 se pueden extraer algunas conclusiones. En primer lugar, hay que reparar en el grado de colaboración a la hora de contestar a las preguntas. Las dignidades y gran parte de los racioneros se muestran poco comunicativos, mientras que son los canónigos los más proclives a informar al obispo y, por lo tanto, a desatender las recomendaciones de confidencialidad que se les hizo. A la hora de evaluar el sentimiento de pertenencia al cabildo, puede decirse que es elevado en las dignidades y en los racioneros, pero en éstos últimos nace de su interés por aferrarse a una condición de capitular que muchas veces se les cuestiona. Entre las dignidades surge por su conciencia de elite religiosa, por saber que ocupan los primeros puestos de la institución. Contemplan al obispo como a un competidor. Además, se saben integrantes de los principales linajes de la ciudad. Por todo lo cual representan la fuerza del poder local frente a la injerencia foránea. Este tipo de sentimiento todavía era muy fuerte a fines del siglo XVI y lo seguirá siendo durante gran parte de la centuria siguiente.

Se desconoce qué conclusión pudo sacar el obispo Dávila de estas respuestas. Quizás consideró que no se trataba de grandes faltas o bien creyó que se ha-

\footnotetext{
45 José Javier RuIZ IbÁÑEZ, Las dos caras de Jano. Monarquía, ciudad e individuo. Murcia, 15881648, pp. 151-153, en especial gráfico n II.1.a.

${ }^{46}$ Francisco Cobos RuIZ DE AdANA, El clero en el siglo XVII. Estudio de una visita secreta a a la ciudad de Córdoba, Córdoba, 1976; María Luisa CANDAU ChaCón, Los delitos y las penas en el mundo eclesiástico sevillano del XVIII, Sevilla, 1993, pp. 118-129.
} 
bían corregido. Lo único constatable es que cuando presentó al cabildo las conclusiones de la visita no señaló nada disciplinario. ${ }^{47}$

LAS FALTAS DE LOS PREBENDADOS, 1592-1622

Numerosos tratadistas y predicadores denunciaron los males y se empeñaron en remediar los desmanes. Dedicar una parrafada a los vicios del clero parecía cosa obligada en todo predicador que se preciara ${ }^{48}$ En 1614 el padre Gondino criticó el comportamiento de ciertos capitulares. El cabildo decide entonces «actuar por los medios que se pueda se procuren remediar las demasias y desordenes en el predicar particularmente en el poco recato con que trata de las personas ecclesiasticas». ${ }^{49}$ Siendo una institución privilegiada y prestigiosa lo eran también sus miembros. Por esta razón, las acusaciones debían seguir un procedimiento. Algunas veces al lanzar estas denuncias, se hacían fuera de lugar y de tiempo, sobre todo cuando eran sospechas contra personas eclesiásticas.

Es lo que sucedió a fines de 1620. El racionero Fernández informó que en

el sermón que predicó ayer el comendador de La Merced avia disfamado a un clerigo e que se entendia claramente lo avia por el racionero Francisco Cano que era bien que el cabildo como agraviado bolviese por sus capitulares muertos puesto de lo que avia dicho era falsedad e mentira como constara de su testamento.

El cabildo acordó elevar una queja al religioso «y para que se enterase de la verdad e que no era ansi como lo avia dicho le mostrasen el dicho testamento».50

Las denuncias y las sospechas, con o sin fundamento, sobre la vidad de los prebendados, motivaron que los sucesores de Sancho Dávila en la mitra no cesaran de pedir a los capitulares que mantuvieran buenas costumbres. Al igual que sucedía en otras catedrales, por ejemplo en Granada, ${ }^{51}$ casi era un ritual que el obispo recién llegado se presentara ante el cabildo y exhortara a sus miembros para que guardaran las buenas costumbres:

El señor obispo entro en cabildo e refirio y propuso de algunas cosas cerca de la vida y costumbres de los eclesiasticos y las ofensas que se hazian a dios nuestro señor que

\footnotetext{
${ }^{47} \mathrm{ACM}$, Actas Capitulares (en adelante, AC), Libro (en adelante, Lib.) no 9, fols. 173v-174r, 4-21592.

48 CARO BAROJA, Las formas complejas, pp. 193-200; la cita en la p. 194.

${ }^{49}$ ACM, AC Lib. ${ }^{\circ}$ 11, fol. 313v, 20-3-1614.

${ }^{50}$ ACM, AC Lib. $\mathrm{n}^{\circ}$ 12, fol. 404r, 1-12-1620.

${ }^{51}$ Rafael Marín López, El cabildo de la catedral de Granada en el siglo XVI, Granada, 1998, pp. 293-321.
} 
oviesse enmienda de aqui adelante y oviese quietud y se quitasen de algunos escandalos e murmuraciones que se causaban entre legos.52

No eran eficaces siempre esos deseos. Se ha confeccionado una lista con las causas incoadas por el provisor contra prebendados entre 1592 y 1622 (Tabla 3). No se incluyen los procesos vistos en otros tribunales: Nunciatura, Rota, Inquisición, ni tampoco los casos en que el cabildo ponía el remedio.

Tabla $\mathbf{n}^{0} 3$

Causas seguidas por el provisor contra capitulares, 1592-1622

\begin{tabular}{|l|c|l|}
\hline NOMBRE & AÑO & FALTA \\
\hline $\mathrm{R}^{\circ}$ Bartolomé Fernández & 1592 & Sin especificar \\
\hline $\begin{array}{l}\text { AC Esteban Guil Riquelme, } \\
\mathrm{C}^{\mathrm{a}} \text { Pedro Martínez Alarcón y } \\
\mathrm{C}^{\circ} \text { Alonso Tirado }\end{array}$ & 1592 & Participación en un ahorcamiento \\
\hline $\mathrm{C}^{\circ}$ Fernando Hoces & 1592 & Heridas a un criado \\
\hline $\begin{array}{l}\mathrm{C}^{\circ} \text { Fernando Hoces y } \\
\mathrm{R}^{\circ} \text { Cristóbal Ibáñez }\end{array}$ & 1595 & Incidentes de palabras en el cabildo \\
\hline $\begin{array}{l}\text { AL Antonio de Roda y } \\
\mathrm{R}^{\circ} \text { Diego Martínez Alarcón }\end{array}$ & 1595 & Participación en el incidente anterior \\
\hline AC Esteban Guil Riquelme $^{\text {AC Esteban Guil Riquelme y }}$ & 1596 & Sin especificar \\
\hline $\mathrm{R}^{\circ}$ Adrián Martínez & 1598 & Incidente de palabras \\
\hline $\mathrm{R}^{\circ}$ Bartolomé Fernández & 1600 & Secuestro, Estupro \\
\hline $\mathrm{R}^{\circ}$ Cristóbal Ibáñez & 1601 & Sin especificar \\
\hline $\begin{array}{l}\text { Deán Alberto Lisón y } \\
\mathrm{R}^{\circ} \text { Rodrigo García de Cáceres }\end{array}$ & 1601 & Pelea entre ellos \\
\hline $\mathrm{R}^{\circ}$ Cristóbal Ibáñez & 1601 & Agresión \\
\hline $\mathrm{R}^{\circ}$ Martín Ponce & 1602 & Sin especificar \\
\hline $\mathrm{R}^{\circ}$ Cristóbal Ibáñez & 1602 & Sin especificar \\
\hline $\mathrm{R}^{\circ}$ Diego Gómez Manchado & 1602 & Amancebamiento \\
\hline Deán Alberto Lisón $^{\mathrm{R}^{\circ} \text { Cristóbal Ibáñez }}$ & 1604 & Incontinencia \\
\hline Deán Alberto Lisón $^{\circ}$ & 1605 & Venta fraudulenta \\
\hline
\end{tabular}

52 ACM, AC Lib. n 11, fol. 471v, 9-3-1609. 


\begin{tabular}{|l|c|l|}
\hline NOMBRE & AÑO & FALTA \\
\hline $\mathrm{R}^{\circ}$ Juan Agustín de Móstoles & 1605 & Sin especificar \\
\hline Deán Alberto Lisón & 1608 & Sin especificar \\
\hline $\mathrm{R}^{\circ}$ Bartolomé Fernández & 1610 & Sin especificar \\
\hline $\mathrm{R}^{\circ}$ Juan Agustín Móstoles & 1611 & Impago \\
\hline Deán Luis Pacheco Arróniz & 1612 & Sin especificar \\
\hline $\mathrm{R}^{\circ}$ Ginés Pastor de Medina & 1613 & Amancebamiento \\
\hline $\mathrm{R}^{\circ}$ Pedro Ortega & 1613 & Amancebamiento \\
\hline $\mathrm{R}^{\circ}$ Diego Gómez Manchado & 1613 & Amancebamiento \\
\hline $\mathrm{C}^{\circ}$ Juan Martínez Caxa & 1615 & Deudas \\
\hline $\mathrm{R}^{\circ}$ Miguel Valcárcel & 1615 & Sin especificar \\
\hline $\mathrm{R}^{\circ}$ Pedro Ortega & 1616 & Juego \\
\hline $\mathrm{R}^{\circ}$ Bartolomé Fernández & 1616 & Agresión \\
\hline $\mathrm{R}^{\circ}$ Melchor Cano & 1616 & Agresión \\
\hline $\mathrm{C}^{\circ}$ Gonzalo Pagán Tirado & 1617 & Incidente de palabras \\
\hline $\mathrm{R}^{\circ}$ Francisco de la Torre & 1617 & Sin especificar \\
\hline $\begin{array}{l}\text { AC Diego de Rueda, } \\
\mathrm{C}^{\circ} \text { Alonso Rodríguez Navarro, } \\
\text { Tesorero Jerónimo Villagutierre } \\
\text { y Co Juan Martínez Balbas }\end{array}$ & 1620 & Sin especificar (pleito con el obispo) \\
\hline Un capitular $^{\mathrm{C}}$ & & \\
\hline $\begin{array}{l}\mathrm{C}^{\circ} \text { Gonzalo Pagán Tirado y } \\
\mathrm{R}^{\circ} \text { Miguel Núñez de Cea }\end{array}$ & 1621 & Pelea entre ellos \\
\hline
\end{tabular}

Fuente: ACM AC Libs. n 9-13.

Para sistematizar todas las informaciones de la tabla 3 y obtener una visión de conjunto, se van a englobar en la tabla 4 los motivos de las causas que juzga el provisor según los grandes apartados de delitos que estableció $\mathrm{M}^{\mathrm{a}}$ Luisa Candau Chacón, ${ }^{53}$ mientras que en la tabla 5 se agruparán los tipos de falta que aparecieron tanto en la visita de 1592 (tabla 2) como los que juzgó el provisor (tabla 3 ).

\footnotetext{
${ }^{53}$ CANDAU Chacón, Los delitos y las penas, p. 90.
} 
Tabla $n^{0} 4$

Tipología de los delitos de los capitulares juzgados por el provisor, 1592-1622

\begin{tabular}{|l|c|c|}
\hline DELITO & CASOS & PORCENTAJE \\
\hline Pendencias & 7 & 31,8 \\
\hline Calumnias e injurias & 4 & 18,2 \\
\hline Sexuales & 6 & 27,3 \\
\hline Juego & 1 & 4,5 \\
\hline Secuestros/Fugas & 1 & 4,5 \\
\hline Económicos & 3 & 13,6 \\
\hline TOTAL & 22 & 99,9 \\
\hline
\end{tabular}

Fuente: ACM, AC Libs. no 9-13.

Con la cautela que impone el alto número de casos en los que no se menciona el delito en que se ha incurrido, hay un primer hecho sorprendente si se recuerda lo expuesto en la visita: sólo en una ocasión se abre proceso por juego. El acusado es el racionero Pedro Ortega: se trata del sobrino del racionero del mismo nombre acusado en 1592. Esta única referencia al juego se completa con la amonestación que hará el cabildo años después, en concreto en 1620, al racionero Ortelano (de éste en la visita de 1592 sí que ya se comentaba que adolecía de este defecto) «para que no tenga el truco ni admita a ninguna persona a jugar en el so pena que se le hara punto quitandole todas las horas». .54

Tabla $\mathbf{n}^{0} 5$

Tipología de los delitos de los capitulares aparecidos en la visita de 1592 y en las causas contra capitulares juzgados por el provisor (1592-1622)

\begin{tabular}{|l|c|c|}
\hline DELITO & CASOS & PORCENTAJE \\
\hline Pendencias & 7 & 17,1 \\
\hline Calumnias e injurias & 4 & 9,8 \\
\hline Sexuales & 13 & 31,7 \\
\hline Juego & 13 & 31,7 \\
\hline Secuestros/Fugas & 1 & 2,4 \\
\hline Económicos & 3 & 7,3 \\
\hline TOTAL & 41 & 100,0 \\
\hline
\end{tabular}

Fuente: ACM, Leg. Adjuntos, Autos de la visita del obispo Sancho Dávila, año 1592 y AC Libs. no 9-13.

${ }^{54}$ ACM, AC Lib. n 12 , fol. 352v, 13-4-1620. 
Entre 1592 y 1622, fueron juzgados veintitrés prebendados en los tribunales diocesanos. No se han incluido los cuatro detenidos en 1620 por un pleito con el obispo porque son consecuencia de un largo conflicto que enfrentó al prelado con el cabildo y que no habría de terminar hasta que en 1622 se firme una concordia. De ellos, ocho son reincidentes. El que se enfrentó más veces a la justicia diocesana, con un total de seis causas, fue el racionero Cristóbal López Ibáñez, quien pasó varias temporadas tanto en las cárceles episcopales como arrestado en su propio domicilio; por estas causas, fue privado de voto activo en el cabildo. ${ }^{55} \mathrm{El}$ racionero Bartolomé Fernández fue juzgado cuatro veces, lo mismo que el deán Lisón. Por último, con tres aparece el arcediano Guil Riquelme y con dos, el canónigo Pagán y los racioneros Móstoles, Ortega y Manchado.

Si se compara la identidad de los acusados en la visita con los que son juzgados en estos treinta años, se comprueba que todos, menos Villacis, habida cuenta que Saorín murió poco después de la visita, aparecen en la lista. Aunque Ortelano tampoco aparece, se sabe que siguió manteniendo su afición al juego. Es decir, se puede hablar de la existencia de un grupo de capitulares poco dispuestos a acomodarse a la conducta clerical que propugnaba el Concilio de Trento.

En cuanto a la categoría de los implicados, los resultados son bastante equilibrados, pues nueve pertenecen a los cuerpos superiores del cabildo: cuatro dignidades y cinco canónigos, en tanto que catorce son racioneros.

Los datos de la tabla 5 muestran que la mayor parte de los delitos corresponden al juego o se relacionan con la conducta sexual, tal y como sucedía en otras diócesis, no sólo en España -cuyo ejemplo más escandaloso se dio en Coria, en donde, además, juego y sexo iban unidos de la mano-, 56 sino también en el resto de Europa..$^{57}$

Por debajo de las faltas por juego y sexo, están las manifestaciones de violencia. El apartado de pendencias engloba desde peleas menores hasta participaciones en asesinatos. Son testimonio del alto grado de violencia que caracterizaba el Antiguo Régimen, con muchos delitos de sangre..$^{58}$ No se ha obtenido más información acerca de la participación de los tres prebendados en el incidente del ahorcamiento. Parece que se trataría de un caso más del furor de la lu-

\footnotetext{
55 ACM, AC Lib. n 10, fols. 171v-172r, 29-10-1602.

56 RodríGUEZ SÁNCHEZ, Hacerse nadie, cit.

57 Regina PÖRTNER, The Counter-Reformation in Central Europe. Styria, 1580-1630, Oxford, 2001, pp. 97-100.

58 Ángel RodrígueZ SÁnchEZ, «La historia de la violencia: Espacios y formas en los siglos XVI y XVII», en Carlos Barros (ed.), Historia a debate, tomo II: El retorno del sujeto, Santiago de Compostela, 1995, pp. 124-127: sobre más de mil noticias sobre actos violentos, establece que los delitos de sangre suponen el $59 \%$ del total de las violencias y el $80 \%$ de la violencia contra las personas.
} 
cha de bandos que sacudió Murcia durante la Edad Moderna. ${ }^{59}$ Se demuestra a las claras el grado con que los eclesiásticos se involucraban en los conflictos sociales de la ciudad. ${ }^{60}$

Merece destacarse dentro de las pendencias el proceso contra el canónigo Hoces por herir a un criado suyo. La Iglesia se preocupó mucho por intervenir dentro de los hogares. ${ }^{61}$ Los criados eran considerados parte integrante de la familia y el padre de familia era responsable de ellos como también lo era de su mujer y sus hijos. ${ }^{62}$ Las relaciones entre criado y señor se movían dentro del mundo de las fidelidades domésticas. ${ }^{63}$ Por lo tanto, el cabeza de familia debía vigilar sus actuaciones. El uso del castigo físico para corregirlos era tolerado. Pero si se sobrepasaba en el castigo, los agredidos podían solicitar el amparo de la justicia eclesiástica. Los tribunales diocesanos están llenos de estos procesos, generalmente abiertos a instancia de las esposas. En el caso que nos ocupa, parece que el doméstico denunció a su señor porque éste había ido demasiado lejos en sus reprimendas.

El segundo gran bloque por el que se juzga a prebendados es el de las faltas de carácter sexual. ${ }^{64}$ En 1613 el provisor decide procesar a tres racioneros acusados de amancebamiento y vida deshonesta. Lo curioso de este episodio es

59 CONTRERAs, Sotos contra Riquelmes, cit.; Guy LEMEUnIER, «Una gente belicosa y de ánimos altivos. Sobre los bandos murcianos de la época moderna» en Economía, sociedad y política en Murcia y Albacete (S. XVI-XVIII), Murcia, 1990, pp. 267-297.

${ }^{60}$ La participación de capitulares en conflictos banderizos no fue ni mucho menos privativa de Murcia y así el mismo fenómeno se daba en León u Oviedo a fines de la Edad Media: José María SANTAmarta Luengos, Señorío y relaciones de poder en León en la Baja Edad Media (Concejo y cabildo catedral en el siglo XV), León, 1993, en especial pp. 83-95; Margarita CUARTAS RIVERO, Oviedo y el principado de Asturias a fines de la Edad Media, Oviedo, 1983, p. 186; María Isabel NiCOLÁs CRISPÍN, Mateo BAUTISTA BAUTISTA y María Teresa GARcía CARCíA, La organizacion del cabildo catedralicio leones a comienzos del S. XV (1419-1426), Salamanca, 1990, pp. 283-286.

61 Jean-Louis FlandRIn, Orígenes de la familia moderna, Barcelona, 1979, p. 157; Ángel RodRíGUEZ SÁNCHEZ, La familia en la Edad Moderna, Madrid, 1996, pp. 25-30

${ }^{62}$ Flandrin, Orígenes de la familia, pp. 183-189. Ángel RoDríguEz SÁNCHEZ, «El poder familiar: la patria potestad en el Antiguo Régimen», Chronica Nova, 18 (1990), pp. 365-380.

63 Antonio Manuel Hespanha, «Carne de uma só carne: para uma comprensào dos fundamentos histório-antroplógicos da família na época moderna», Análise Social, 123-124 (1993), pp. 967-968.

${ }^{64}$ Este tipo de faltas fue muy habitual en el territorio peninsular durante la Edad Media ya que en el siglo XV muchos capitulares vivían amancebados: María Isabel NiCOLÁs CRISPíN, Mateo BAUTISTA Bautista y María Teresa García CARcía, La organización del cabildo, p. 282; Margarita CuARTAS RIVERo, Oviedo y el principado, p. 186. Aunque el Concilio de Trento corrigió algo, no pudo desterrarlo por completo y todavía en el siglo XVIII se abrían causas contra clérigos por estos motivos, las cuales llegaron a representar en la diócesis de Sevilla el 20 por 100 del total: CANDAU CHACón, Los delitos y las penas, pp. 90 y 219-312. En otros cabildos se luchó contra estas faltas: Tomás VILLACORTA RoDRÍGUEZ, El cabildo de la catedral de León. Estudio histórico-jurídico, siglos XII-XIX, León, 1974, pp. 323-326; Rafael VÁzQuEz LESMES, Córdoba y su cabildo catedralicio en la modernidad, Córdoba, 1987 , p. 126. 
que puso la denuncia el alcalde mayor. ${ }^{65}$ Se comprueba así cómo la Monarquía estaba implicada en la vigilancia de las buenas costumbres y contribuía a que las reformas tridentinas fueran calando en el tejido social. Un suceso, cuando menos raro, y que no aparece en la tabla 3 , es el proceso que contra el deán Lisón se siguió «sobre y en razon de un matrimonio clandestino que habia fecho» sin desvelar su condición clerical. ${ }^{66}$ Como sucedía con las promesas incumplidas, ${ }^{67}$ en este tipo de causas también se juzgaban las relaciones sexuales consumadas por el clérigo de forma ilícita.

El caso más espectacular fue el del medio racionero Bartolomé Fernández. A finales de 1600, el cabildo recibe un requerimiento del provisor para que se nombre un adjunto que vea junto a él

el pleito criminal que trato con Bartolome Fernandez sobre el rapto estupro sacrilegio y concubinado que cometio con Ana Maria donada del conbento de sancta ysabel desta ciudad sacandola de la dicha clausura y dandole para ello llave y manto y el fabor necessario.

A partir de ese momento, la táctica del racionero Fernández fue poner todas las trabas posibles a la instrucción del proceso. Pese a todo, el provisor comunicó en abril de 1602 al cabildo la sentencia, por la cual despojó de sus beneficios a Fernández y ordenó proveer su prebenda. El acusado, antes de que se hiciera pública la sentencia, había conseguido huir y logró presentarse ante el nuncio para que interviniese en su causa. En Murcia mientras, el cabildo aceptó los planteamientos del fiscal y se declaró vacante la media ración de Fernández. El día elegido para la elección de un nuevo medio racionero, Antonio Fernández, padre del despojado Bartolomé y escribano público del Número y también escribano de las rentas capitulares, se presentó ante el cabildo por sí mismo y en nombre de su hijo dijo que:

aora a benido a mi noticia que tratan y pretenden hacer probyssion de la dicha racion no lo pudiendo ni debiendo hacer porque el dicho delicto de concubinato es leue y no tiene pena de pribacion ypso jure ni por sentencia y quando la tubiera por la apellacion quedo suspenso el efecto de la dicha sentencia y la causa debuelta al superior y ansi en ninguna manera se puede ni deve innobar pendiente appellacion ni hacer probyssion de benefficio que esta por vacar biviendo el posehedor por tanto pido y suplico a los dichos señores y hablando como debo rrequiero las ueces que puedo y en derecho deuo no probean la dicha rracion ni en ello hagan nobedad hasta que la causa se determine por el superior.

Esta petición demuestra que un padre hacía cualquier cosa por su hijo: en este caso, omite cualquier referencia a la grave acusación de crímenes como se-

${ }^{65}$ ACM, AC Lib. $\mathrm{n}^{\circ}$ 11, fol. 240v, 1-2-1613.

${ }^{66}$ ACM, Leg. n $^{\circ} 295,29-7-1613$.

${ }^{67}$ CANDAu Chacón, Los delitos y las penas, pp. 290-302.

Hispania Sacra, LXII

125, enero-junio 2010, 157-179, ISSN: 0018-215-X 
cuestro, estupro y sacrilegio. Segundo, que el tan requerido juramento de secreto a los capitulares era quebrantando con mucha frecuencia. Parece además que el racionero Fernández contaba con el apoyo y simpatía de algunos miembros del cabildo. Pero quizás lo más interesante sea que revela con claridad meridiana las dificultades que encontraban las disposiciones tridentinas para modificar los hábitos del clero: pues, para muchos clérigos, el delito de concubinato era considerado como leve. Quizás por eso las faltas de los clérigos en materia sexual no concitaban mucho interés en los visitadores eclesiásticos. ${ }^{68} \mathrm{Si}$ así pensaban las personas del ámbito eclesiástico, ¿cuál sería entonces el sentir del común de la población? Por esta razón, se puede considerar acertada la reflexión de Josué Fonseca cuando señalaba que la vida licenciosa del clero en materia sexual se trataba más de un problema de mentalidad que de contravención moral. ${ }^{69}$ No es extraño, por tanto, que siguieran produciéndose faltas de este tipo, como bien se puede apreciar en el estudio realizado por María Luisa Candau para la diócesis de Sevilla en el siglo XVIII. Aquí los delitos de naturaleza sexual representaban el 19\% de los procesos criminales contra clérigos, el segundo tipo más frecuente de faltas. ${ }^{70}$

Las interminables querellas sobre la jurisdicción, aparte de retrasar el programa de reformas del Concilio, favorecían en última instancia al infractor. Entonces, también los defectos de forma invalidaban las condenas. Esto salvó a Bartolomé Fernández. En efecto, el 17 de octubre de 1602, el provisor comunicó al cabildo el auto del nuncio por el que declaraba nula la sentencia del provisor y obligaba a restituir a Bartolomé Fernández su ración..$^{71}$

La letra del espíritu tridentino quedó más que tachada. Bartolomé Fernández ocupó su prebenda hasta el año 1629 cuando fue asesinado. Durante este lapso fue acusado, por lo menos, en dos ocasiones más: una en 1610 y otra en 1616 a causa de una agresión. Ni en el momento de su muerte fue un prototipo de eclesiástico que pretendía Trento.

\section{Algunas CONCLUSIONES}

En las páginas precedentes queda demostrado que ciertos miembros del cabildo catedral de Murcia no vivieron de acuerdo a la dignidad del estado al que pertenecían ni se acercaban al modelo de clérigo que el Concilio de Trento tra-

${ }^{68}$ Marc R. Forster, Catholic revival in the Age of the Baroque: religious identity in Southwest Germany, 1550-1750, Cambridge, 2001, p. 44.

69 Josué FonseCa MARTínez, El clero en Cantabria en la Edad Moderna, Santander, 1996, p. 166.

${ }^{70}$ CANDAU CHACón, Los delitos y las penas, pp. 89 y 219-312.

${ }^{71}$ ACM, AC Lib. no 10 . fols. 167r-172v, 17-10-1602. 
taba de implantar. La reforma tridentina tuvo muchos claroscuros. Los prebendados de Murcia no fueron un caso excepcional dentro del clero hispano. Durante el siglo XVII y por toda la Monarquía se daban conductas censurables. Conocemos la situación en Galicia, Cantabria y Andalucía. ${ }^{72}$

Su origen, según Helen Rawlings, estaría en los graves defectos de infraestructura y en los numerosos conflictos de jurisdicción que la Iglesia española tenía; por eso las medidas reformistas sólo obtuvieron un éxito parcial. Los rectores de la Iglesia española llegaron a asumir que la elevación profesional, pastoral y apostólica del clero en la época postridentina habría de ser un proyecto a largo plazo. ${ }^{73}$

Aceptada la validez de esta explicación, habría que contar con otros factores. Una primera hipótesis tiene que ver con el hecho de que una gran mayoría de los clérigos carecían de vocación, pues muchos se habían ordenado por imposición, generalmente familiar. Eso explicaría que no se sintieran atraídos, ni obligados, por el ideal de perfección que pretendía Trento. Algunos vivían como seglares y sus lazos con el mundo secular eran sólidos, fortísimos. Estos aspectos se acentuaban en el caso de los prebendados que disponían de mucho tiempo libre y algunos lo llenaron de forma poco edificante. Se consideraban unos privilegiados dentro de la sociedad por pertenecer a una institución de prestigio y a unas familias que pertenecían a las oligarquías locales. Con frecuencia, pesaba más en ellos esta última condición que la de eclesiástico. Por ejemplo, Esteban Guil Riquelme actuaba movido más por ser un miembro del importante linaje de los Riquelme que por ser arcediano de Cartagena. Primero era un pariente, un miembro de una familia, de un linaje y de un bando y, después, era un clérigo.

Contra esto iban los decretos tridentinos, que pretendían profesionalizar al clérigo y separarlo de la sociedad. El choque era inevitable. Podían pertenecer al estamento eclesiástico, con un estatus privilegiado que alimentaba su conciencia de superioridad social, pero los clérigos, y menos los capitulares, no estaban dispuestos a abandonar «el mundo» y sus negocios.

Con las limitaciones que impone la escasez documental, puede creerse que las faltas de los prebendados fueron disminuyendo a lo largo del siglo XVII y

72 Ofelia Rey CASTELAO, «El clero urbano compostelano a fines del siglo XVII: Mentalidades y hábitos culturales», en Historia social de Galicia en sus fuentes de protocolo, Santiago de Compostela, 1981, pp. 495-519; Baudilio BARREIRO MALlóN, «Sínodos, pastorales y expedientes de órdenes: tres indicadores de religiosidad en el noroeste de la península» en León Carlos ÁLVAREZ SANTALó, Ma Jesús BuXó y Salvador RodrígUEZ BECERRA (coords.), La religiosidad popular, vol. II, Vida y muerte: la imaginación religiosa, Sevilla, 1989, pp. 72-95; COBOS RUIZ DE ADANA, El clero, cit.; FonSECA MonTES, El clero en Cantabria, pp. 158-181.

${ }^{73}$ Rawlings, Church, Religion and Society, pp. 76-77.

Hispania Sacra, LXII

125, enero-junio 2010, 157-179, ISSN: 0018-215-X 
que se produjo una mejora general en el nivel del clero, tal y como indica Arturo Morgado. ${ }^{74}$ Lo cual no significa que consiguieran desterrarse las conductas desordenadas, como bien demuestran numerosos trabajos; ${ }^{75}$ aunque también es posible que esto sólo se diera en una minoría. ${ }^{76} \mathrm{~A}$ pesar de lo cual, lo cierto es que no se llegó a alcanzar en la España moderna la separación entre clérigos y el resto de la sociedad, tal y como quería el concilio de Trento. Su extracción familiar, su falta de vocación y la ausencia de una formación previa a su ingreso en el clero pueden explicar la resistencia a la reforma.

En conclusión, luces y sombras en la difícil aplicación del Concilio de Trento a la realidad eclesiástica hispana del último cuarto del siglo XVI y primeros años del siglo XVII. ${ }^{77}$ Y parece que, en líneas generales, a los cabildos catedralicios y a sus prebendados, les costaba salir de las sombras.

\footnotetext{
${ }^{74}$ Morgado García, «El estamento eclesiástico», p. 498.

75 Isidro DUBERT GARCÍA, «La domesticación, la homogeneización y la asimilación de las conductas del clero gallego del Antiguo Régimen a la idealidad del modelo tridentino, 1600-1850», en José Manuel DonéZAR y Manuel Pérez Ledesma (eds.), Antiguo Régimen y Liberalismo. Homenaje a Miguel Artola, II: Economía y sociedad, Madrid, 1995, pp. 477-495; idem, «Los comportamientos del clero urbano en Galicia: el ejemplo de Santiago de Compostela», Compostellanum, 31 (1986), pp. 443 455; María del Pilar Pueyo Colomina, Iglesia y sociedad zaragozanas a mediados del siglo XVIII, Zaragoza, 1991; FonseCA Montes, El clero en Cantabria, cit.; CANDAU ChACón, Los delitos y las penas, cit.

76 Jesús Bravo Lozano, Familia busca vivienda. Madrid, 1670-1700. Madrid, 1992; Francisco J. SANZ DE LA Higuera, «"En Casa [, Cama] y Compañía”. Yacer a lomos del siglo XVIII en los hogares eclesiásticos burgaleses», Hispania Sacra, LVIII, 118 (2006), pp. 545-577.

77 Anthony D. Wright, Catholicism and Spanish society under the Reign of Philip II 1555-1598, and Philip II 1598-1621, Nueva York, 1991; José García Oro y María José Portela SiLVA, «Felipe II y las iglesias de Castilla a la hora de la reforma tridentina», Cuadernos de Historia Moderna, 20 (1998), pp. 9-32; Ignasi FERnÁNDEZ TERRICABRAS, «Éxitos y fracasos de la Reforma católica. Francia y España (siglos XVI-XVII)», Manuscrits, 25 (2007), pp. 129-156; Camilo FernándeZ CorTizo, «Para que esta gente bárbara fuese política y doméstica y enseñada en la doctrina cristina: Iglesia, Estado y reforma religiosa en Galicia (siglos XVI-XVII)», Manuscrits, 25 (2007), pp. 157-186.
} 